Defense Threat Reduction Agency

8725 John J. Kingman Road, MS-6201

Fort Belvoir, VA 22060-6201

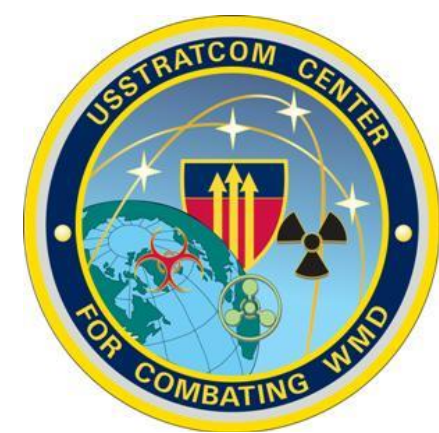

DTRA-TR-13-51

\title{
Search for New Highly Energetic Phases under Compression and Shear
}

Distribution Statement A. Approved for public release; distribution is unlimited.

May 2015

Valery I. Levitas and

Yanzhang Ma

Prepared by:

lowa State University

2028 Black Engineering

Building

Ames, IA 50011 


\section{DESTRUCTION NOTICE:}

Destroy this report when it is no longer needed.

Do not return to sender.

PLEASE NOTIFY THE DEFENSE THREAT REDUCTION

AGENCY, ATTN: DTRIAC/ J9STT, 8725 JOHN J. KINGMAN ROAD, MS-6201, FT BELVOIR, VA 22060-6201, IF YOUR ADDRESS

IS INCORRECT, IF YOU WISH THAT IT BE DELETED FROM THE

DISTRIBUTION LIST, OR IF THE ADDRESSEE IS NO

LONGER EMPLOYED BY YOUR ORGANIZATION. 


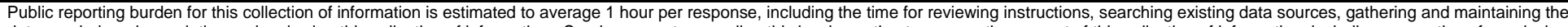

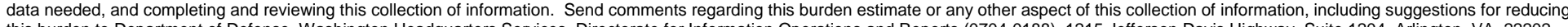

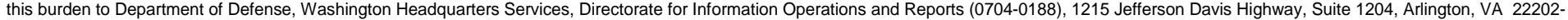

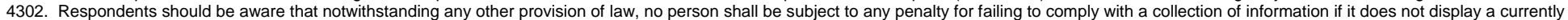
valid OMB control number. PLEASE DO NOT RETURN YOUR FORM TO THE ABOVE ADDRESS.

\begin{tabular}{|l|l|l}
\hline 1. REPORT DATE (DD-MM-YYYY) & 2. REPORT TYPE & 3. DATES COVERED (FrOm - To)
\end{tabular}
00-05-2015

4. TITLE AND SUBTITLE

Search for New Highly Energetic Phases under Compression and Shear

Technical 5a. CONTRACT NUMBER

5b. GRANT NUMBER

HDTRA1-09-1-0034

5c. PROGRAM ELEMENT NUMBER

\section{AUTHOR(S)}

Dr. Valery Levitas (lowa)

Dr. Yanzhang Ma (Texas)

5e. TASK NUMBER 5d. PROJECT NUMBER

5f. WORK UNIT NUMBER

8. PERFORMING ORGANIZATION REPORT NUMBER

\section{PERFORMING ORGANI}

2028 Black Engineering Building

Ames, lowa 50011
Texas Tech University

7th St. \& Boston Ave.

Lubbock, Texas 79409

\section{SPONSORING I MONITORING AGENCY NAME(S) AND ADDRESS(ES)}

Defense Threat Reduction Agency

8725 John J. Kingman Road STOP 6201

Fort Belvoir, VA 22060

$\mathrm{PM} /$ Suhithi Peiris
10. SPONSOR/MONITOR'S ACRONYM(S)

DTRA

11. SPONSOR/MONITOR'S REPORT NUMBER(S)

DTRA-TR-13-51

\section{DISTRIBUTION / AVAILABILITY STATEMENT}

Distribution Statement A. Approved for public release; distribution is unlimited.

\section{SUPPLEMENTARY NOTES}

\section{ABSTRACT}

In this project, we performed the first search for highly energetic high pressure metastable phases obtained under compression and plastic shear in a rotational diamond anvil cell (RDAC) in azides. We combined experimental, theoretical, and modeling efforts to gain fundamental information on shear-induced PTs in materials with potentially highly energetic phases and on the ways to retain them under ambient conditions.

\section{SUBJECT TERMS}

Green Munitions RDAC Nanoscale Nucleation

\begin{tabular}{|c|c|c|c|c|c|}
\hline \multicolumn{3}{|c|}{ 16. SECURITY CLASSIFICATION OF: } & \multirow{2}{*}{$\begin{array}{c}\text { 17. LIMITATION } \\
\text { OF ABSTRACT } \\
\text { SAR }\end{array}$} & \multirow[t]{2}{*}{$\begin{array}{l}\text { 18. NUMBER } \\
\text { OF PAGES }\end{array}$} & $\begin{array}{l}\text { 19a. NAME OF RESPONSIBLE PERSON } \\
\text { Suhithi Peiris }\end{array}$ \\
\hline $\begin{array}{l}\text { a. REPORT } \\
\text { Unclassified }\end{array}$ & $\begin{array}{l}\text { b. ABSTRACT } \\
\text { Unclassified }\end{array}$ & $\begin{array}{l}\text { c. THIS PAGE } \\
\text { Unclassified }\end{array}$ & & & $\begin{array}{l}\text { 19b. TELEPHONE NUMBER (include area } \\
\text { code) } \\
703-767-4732\end{array}$ \\
\hline
\end{tabular}


CONVERSION TABLE

Conversion Factors for U.S. Customary to metric (SI) units of measurement.

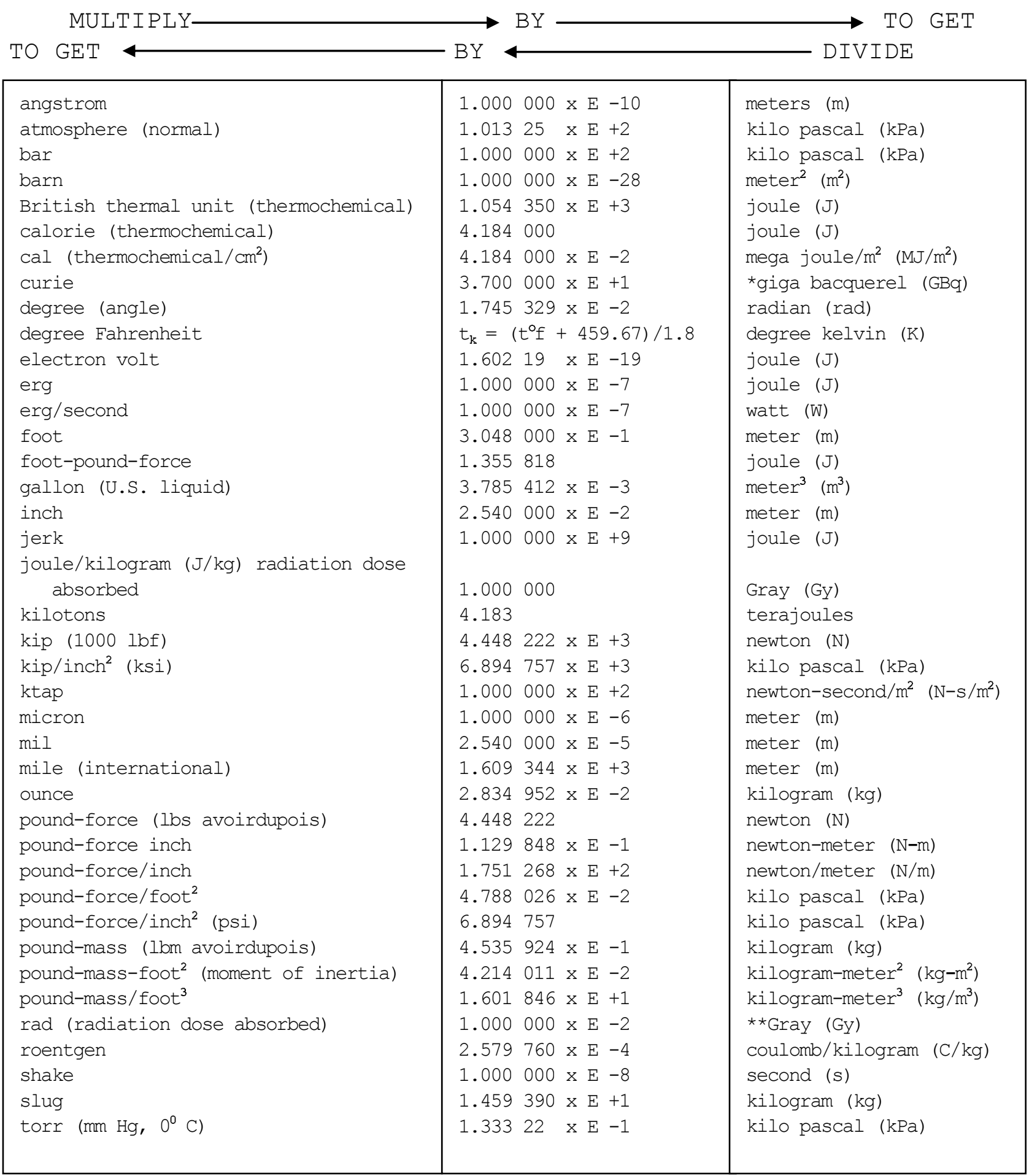

*The bacquerel (Bq) is the SI unit of radioactivity; $1 \mathrm{~Bq}=1$ event/s.

**The Gray (GY) is the SI unit of absorbed radiation. 


\section{Defense Threat Reduction Agency \\ Grant HDTRA1-09-1-0034 \\ Search for New Highly Energetic Phases under Compression and Shear}

Started in May 2009

PI: Valery I. Levitas

Schafer 2050 Challenge Professor

Iowa State University

Department of Mechanical Engineering

Department of Aerospace Engineering

Department of Material Science and Engineering

2028 Black Engineering Building

Ames, Iowa 50011-2161

Phone: (515) 294-9691 Fax: (801) 7880026

Email: vlevitas@iastate.edu

http://www.me.iastate.edu/index.php?id=6338.html

Co-PI: Yanzhang Ma

Associate Professor

Department of Mechanical Engineering

Texas Tech University

7th St. \& Boston Ave.

Lubbock, Texas 79409

Phone (806) 7423563 ext. 243 Fax: (806) 7423540

Email: y.ma@ttu.edu 


\section{Executive Summary}

(a) A simple macroscopic theory for stra in-induced phase tran sformations under high pressure is developed.

(b) The corresponding finite element algorithms and subroutines are developed.

(c) Problems on compression and shear of a sample in rotational diamond anvil cell are solved. The results change the fundamental understanding of interpretation of experimentally observed effects and measurements and the extracting of information on material behavior from sample behavior.

(d) Nanoscale phase field theory for solid-solid transformations for the most general case of large elastic and transformation strains, and different elastic properties of phases is developed.

(e) The corresponding finite element algorithms and subroutines are developed. Model problems on martensitic microstructure evolution are solved.

(f) Experimental approaches to study strain -induced phase transformations in potentially energetic materials are refined.

(g) Experiments on $\mathrm{NaN}_{3}, \mathrm{NaN}_{3}+\mathrm{N}_{2}$ mixture, and $\mathrm{AgN}_{3}$ are performed under hydrostatic compression up to $77 \mathrm{GPa}$ and under shear.Various phase transfor mations, including amorphization, are obtained in both materials under various compression-shear paths.

(h) In add ition to plan, experiments on $\mathrm{KN}_{3}$ and $\mathrm{CsN}_{3}$ are performed under hydrostatic compression up to $50 \mathrm{GPa}$.

(i) In addition to plan, theory of surface-induced phase tran sformation is developed and checked for pre-melting and melting of Al.

(j) In addition to plan, barrierless nucleation near nanovoids is studied.

\section{Introduction}

One of the main DoD missions in high energy density materials is to find new energetic materials with 10 times the TNT energy release and with enhanced stability, reduced sensitivity, and satisfying "green munitions" requirements. e.g., the recent ARL effort is to synthesize polymeric nitrogen (and $\mathrm{N}_{2} / \mathrm{H}_{2}$ ), which is expected to have 5 times the TNT energy release, using the diamond anvil cell. Polymeric $\mathrm{N}_{2}$ appears above $110 \mathrm{GPa}$ pressure and above the temperature of $2000 \mathrm{~K}$ but cannot be retained under ambient conditions. In these studies, phase transformations (PTs) are obtained in a diamond anvil cell under high quasi-hydrostatic pressure. While it is recognized that plastic shear can (a) reduce PT pressure by a factor of 2-10, (b) drastically accelerate the kinetics of PT, (c) lead to new phases, and (d) replace reversible PTs with irreversible ones for some materials, we are not aware of any study of PT under pressure and shear with the goal of finding highly energetic metastable phases.

In this project we performed the first search for highly energetic high pressure metastable phases obtained under compression and plastic shear in a rotational diamond anvil cell (RDAC) in azides. We combined experimental, theoretical, and modeling efforts to gain fundamental information on shear-induced PTs in materials with potentially highly energetic phases and on the ways to retain them under ambient conditions. 


\section{Methods and Results \\ Theoretical and Computational Studies}

We pursued two goals:

1. Develop the first nanoscale theory and simulation technique based on phase field approach in order to better understand the main reasons and $\mathrm{m}$ echanisms for plastic straininduced nucleation and growth of the high-pressure phase. Hypothetically, nucleation may occur at dislocation pile ups, nanovoids, grain bound aries and other in terfaces. Our tasks included development of large strain form ulation, introduction of the interface tension and stresses, description of surface-induced phenom ena (as the first step toward desc ription of the grain boundary-induced nucleation), and simulation of multivariant martensitic phase trans formation. Since experimental results on surface-induced transformations in solids are absent, we also developed theory for surface-induced melting and obtained good agreement with experiments. Also, to resolve main challenges of the theory of nucleation in elastoplastic materials, we started with the simplest phase transformations, namely, sublimation and melting.

2. Develop the macroscale theory and fini te element method (FE M) approaches to describe behavior of a sample under compression and torsion in RDAC. This is important for extraction and interpretation of experim ental data and understanding of macroscopic reasons for strain-induced promotion of PTs.

The following results have been obtained:

(a) The simplest macroscopic theory for strain-induced phase transformations under high pressure is developed. It couples large plastic deformations of materials with strain-induced kinetic of phase transformations[3,6,7,21].

(b) The finite element algorithms and subroutines are developed for the above theory. The procedure is found for implementation of th ese algorithms in the finite elem ent code ABAQUS [3,5-7,21].

(c) Problems on com pression and shear of a sample in rotational diamond anvil cell are solved. The results change the fundamental understanding of interpretation of experimentally observed effects and measurements and the extracting of information on material behavior from sample behavior. These effects include nontrivial, nonlinear interac tion between strongly heterogeneous stress and plastic strain tensor fiel ds and phase transformation kinetics, the effect of change of material strength during phase transform ation, the simultaneous occurrence of direct and reverse phase transform ations in different regions, strong strain localization, and pressure self-multiplication. Various experimentally observed effects are reproduced and interpreted. The obtained results also represent a tool for designing experiments for different purposes and for controlling phase transformations [3,5-7,21].

We found that in the regions with strong gradients of concentration of phases (at the plateaus) and (in case of weaker product phases) in the entire sample, a traditional simplified equilibrium equation leads to incorrect results, which caused major confusion in the field. Experimentally observed plateaus in the pressure-distribution have been reproduced in our calculation. For the case when the high-pressure phase is significantly stronger than the lowpressure phase, the plateau indeed corresponds to the two-phase region between completely transformed and non-transformed material. Pressure at plateaus varies slightly between two characteristic pressures in kinetic equation for strain-induced transformations, which allows us to identify these two key material parameters through experiment.

Pressure grows strongly during the torsion and phase tran sformation, despite the volume decrease due to transformation. This result is not in contradiction with the Le Shatelie principle 
because the thermodynamics of heterog eneous, strain-induced phase transform ations differs significantly from classical therm odynamics, corresponding instead to the experimentally observed pressure self-multiplica tion effect. Al so, during torsion, the thickness of a sam ple is reduced, and the high-pressure phase radially flows to the low-pressure region, where straininduced reverse transformations start. Thus, both direct and reverse phase transformations occur simultaneously in different regions. When the high-pressure phase is significantly weaker than the low-pressure phase, calculations reproduce an experimentally observed, highly irregular pressure field and plateau, and suggest when it is possible to extract two characteristic pressures and when pressure at steps does not have any specific meaning for strain-induced transformations. It is surprising, but in this case torsion does not promote the phase transformations in comparison with compression. Obtained results open ways to extract information on $\mathrm{m}$ aterial properties and phase transformation kinetics by coupling simulations and experiment, as well as to control phase transformations by controlling the loading path.

(d) Nanoscale phase field theory for solid-solid transformations for the most general case of large elastic and transformation strains, and different elastic properties of phases is developed [1,9]. This break-through in phase field theory will allow us to accurately study real high-pressure phase transformations at thenanoscale. The corresponding finite element algorithms and subroutines are developed. Model problems on martensitic microstructure evolution are solved and the qualitative difference between simplified small-strain theory and our la rge-strain theory are demonstrated.

(e) Interface propagation in the fram ework of the developed phase field theory (but for small strains) is studied in de tail [2]. The long-standing problem of introducing an atherm al resistance to the interface propagation into the phase field theory of martensitic phase transformations is solved. This allowed us to correctly described multiphase stationary microstructures and stress hysteresis.

(f) Problems on barrierless nucleation near s ingle and multiple spherical and ellipsoidal nanovoids are solved. Nanovoids represent a nontrivial defect, which may exist under high pressure and which do not change pressure around them, but produce high nonhydrostatic stresses [1].

(g) Theory of barrierles s surface-induced phase transformations in solids is developed [8]. It takes into accou nt in a non-contrad ictory way variation in surface energy d uring phase transformation. It may serve as a potential mechanism of barrierless nucleation at grain boundary, when its energy reduces during phase transformation. To check validity of the theory, it is applied to descriptions of pre-melting and melting of Al nanoparticles [14]. Good correspondence with experiments is obtained for the thickness of molten layer versus temperature and for melting temperature versus particle size.

(h) Phase field theory is advanced in a way that one can control the martensite-martensite interface energy independent of the austenite-martensite interphase energy $[8,15]$. Detailed study of the effect of martensite-martensite interface energy on the evolution of martensitic microstructure in a nanograin is performed [15].

(i) Strong, surprising, and multifaceted effects of the width of the external surface layer and internal stresses on surface-induced pre-transformation and PTs are revealed using our further developed phase-field approach [18]. Multiple morphological transitions in the surface layer are found. These results are relevant for study of grain-boundary-induced nucleation.

(j) Various conceptual problems related to nucleation in elastoplastic materials are formulated and resolve on the simples PTs like sublimation and melting [19,20]. 
(k) Importance of dynamic formulation for phase field approach to PT in solid is demonstrated [22].

\section{I. $\mathrm{NaN}_{3}$}

\section{Experimental Studies}

\section{(a) Experimental study of $\mathrm{NaN}_{3}$ under hydrostatic compression [23].}

$\mathrm{NaN}_{3}$ sample has been compressed in surrounding medium of neon, argon, nitrogen, and mixture of methanol and $m$ ethanol. We found a num ber of phase tran sitions of $\mathrm{N}_{\mathrm{aN}}$. As is identified through synchrotron X-ray diffraction (F igure I-1), the phase transitions appeared at 0.2-0.3 GPa and $16-18.3 \mathrm{GPa}$ (Figure I-2). The phase between $\sim 0.3$ to $18.3 \mathrm{GPa}$ is identified to be the reported low temperature phase, that has a monoclinic structure. At pressures higher than 18.3 GPa, we start to see significant change of x-ray diffraction pattern. The peaks become much broader and the intensity significantly reduced (as observed in the experim ents).This is an indication of disordering of $\mathrm{NaN}_{3}$, corresponding to a new phase (phase III). Further work needs to be don e to solve the structure. However, the pha se boundaries of these phases have been determined as shown in Figure I-2. The bulk modulus of Phase II is determined to be $33.8 \mathrm{GPa}$.
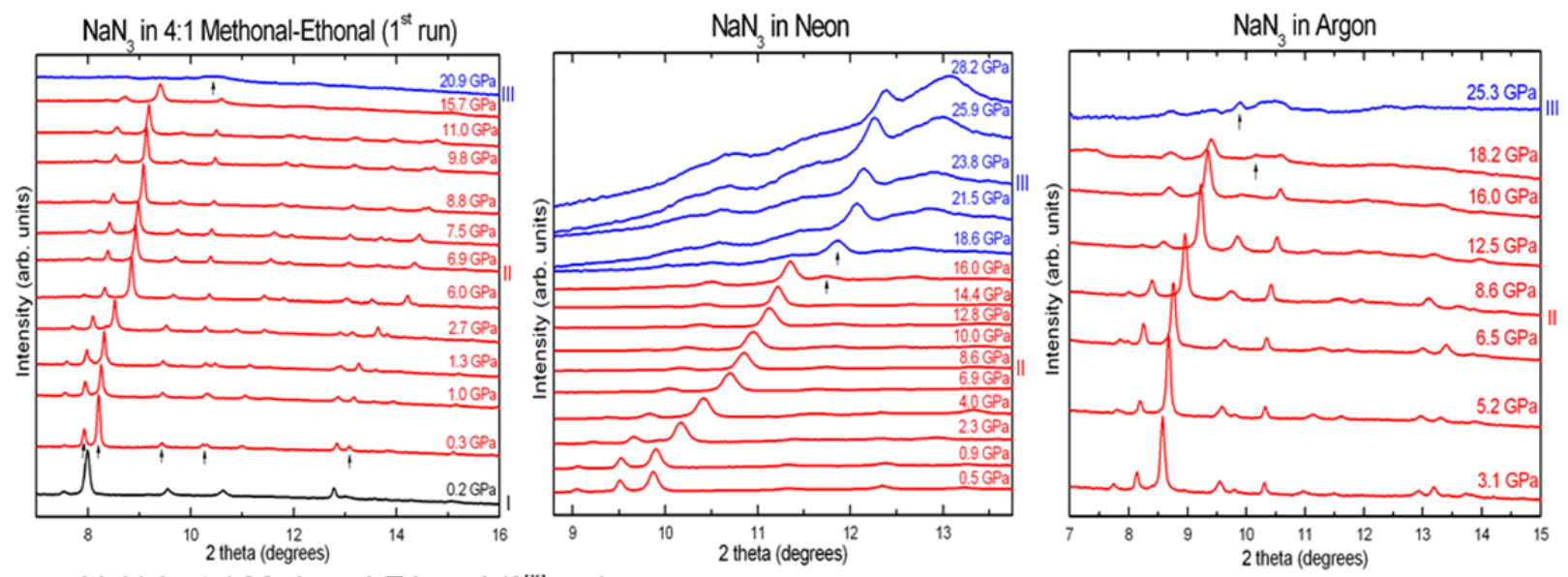

$\mathrm{NaN}_{3}$ in 4:1 Methanol-Ethanol (2 $2^{\text {nu }}$ run $)$
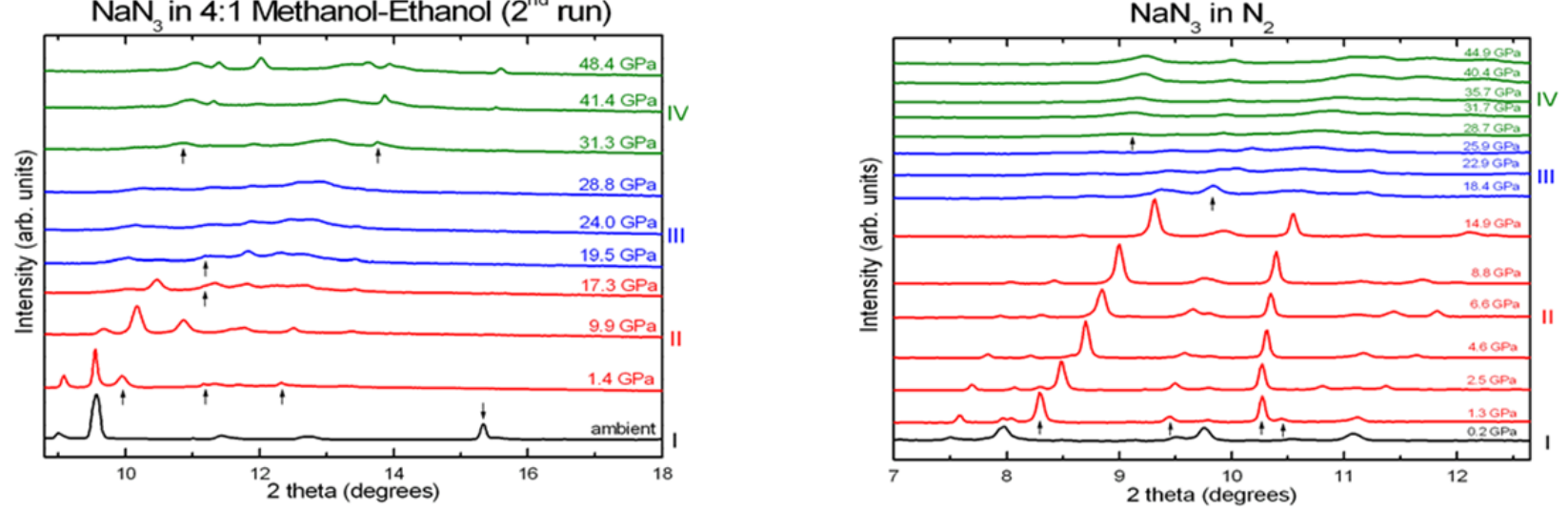

XRD patterns of $\mathrm{NaN}_{3}$ in various pressure mediums. Different phases are demonstrated by different colors.

Figure I-1. X-ray diffraction spectra of $\mathrm{NaN}_{3}$ at pressures in different pressure medium. The numbers and word mark the pressure in GPa. 


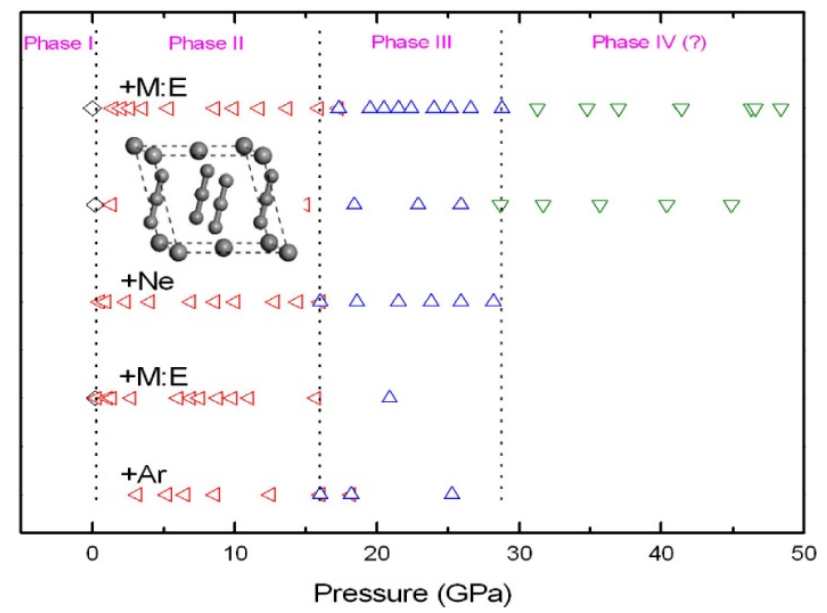

Figure I-2. The room temperature phase diagram of $\mathrm{NaN}_{3}$. Letters mark the material surrounding the sample as pressure transmitting media.

\section{(b) Shear effect on phase transition of $\mathrm{NaN}_{3}$ by X-ray [24].}

Shear effect on phase transition of $\mathrm{NaN}_{3}$ has been explored with a rotational diamond anvil cell (Figure I-3). A $2.2 \mathrm{GPa}$, a 40-degree rotation of an anvil led to pressure increased to $4 \mathrm{GPa}$. At $9.9 \mathrm{GPa}$, a rotation of 20 degree resulte $\mathrm{d}$ in complete phase tr ansition to phase III. Thus, shear reduced transformation pressure for initiation of phase III from 16 to 9.9 GPa. Pressure increases during phase transition to $16.5 \mathrm{GPa}$. After the sample was quenched to room pressure with another 20 degree rotation, amorphous phase was obtained.

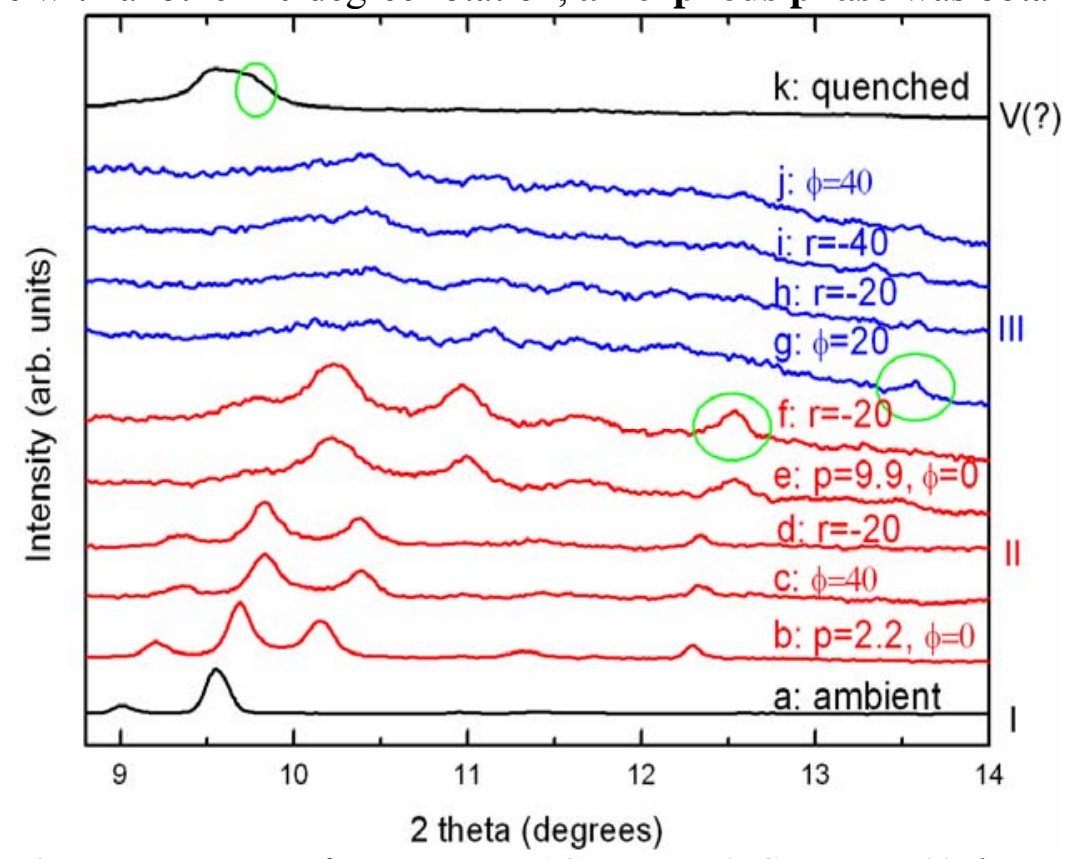

Figure I-3. XRD patterns of $\mathrm{NaN}_{3}$ in RDAC. $a: p=0 \mathrm{GPa}, \varphi=0^{\circ}$; $b$ : pressure increase (PI), $p=2.2$ $G P a, \varphi=0^{\circ} ; c: \varphi=40^{\circ}$ after conditions described by $b$ at $r=0$; $d$ : same as $c, r=20 \mu \mathrm{m}$; $e: P I, p=9.9$ GPa, $\varphi=0^{\circ}, r=0$; $f$ : same as e, $r=20 \mu \mathrm{m} ; \mathrm{g}: \varphi=20^{\circ}$ after $e, r=0$; $h$ : same as $g, r=20 \mu \mathrm{m}$; $i$ : same as $g, r=40 \mu \mathrm{m} ; j: \varphi=40^{\circ}$ after $g, r=0 ; k$ : quench to ambient pressure. Different phases are demonstrated by different colors. 
(c) Raman spectrum measurements under pressure and shear of $\mathrm{NaN}_{3}$ [24].

We performed a Raman scattering measurement of $\mathrm{NaN}_{3}$ under pressure and shear (Figure I-4). We revealed that

- The sample becomes amorphous with extensive shear stress initialized at $44.8 \mathrm{GPa}$;

- The Lattice modes vanish rapidly along with rotation;

- The N-N vibration mode vanishes with extensive rotation initialized at 44.8 GPa.

- The amorphous phase can be quenched at least to $21.3 \mathrm{GPa}$ (Figure I-5).

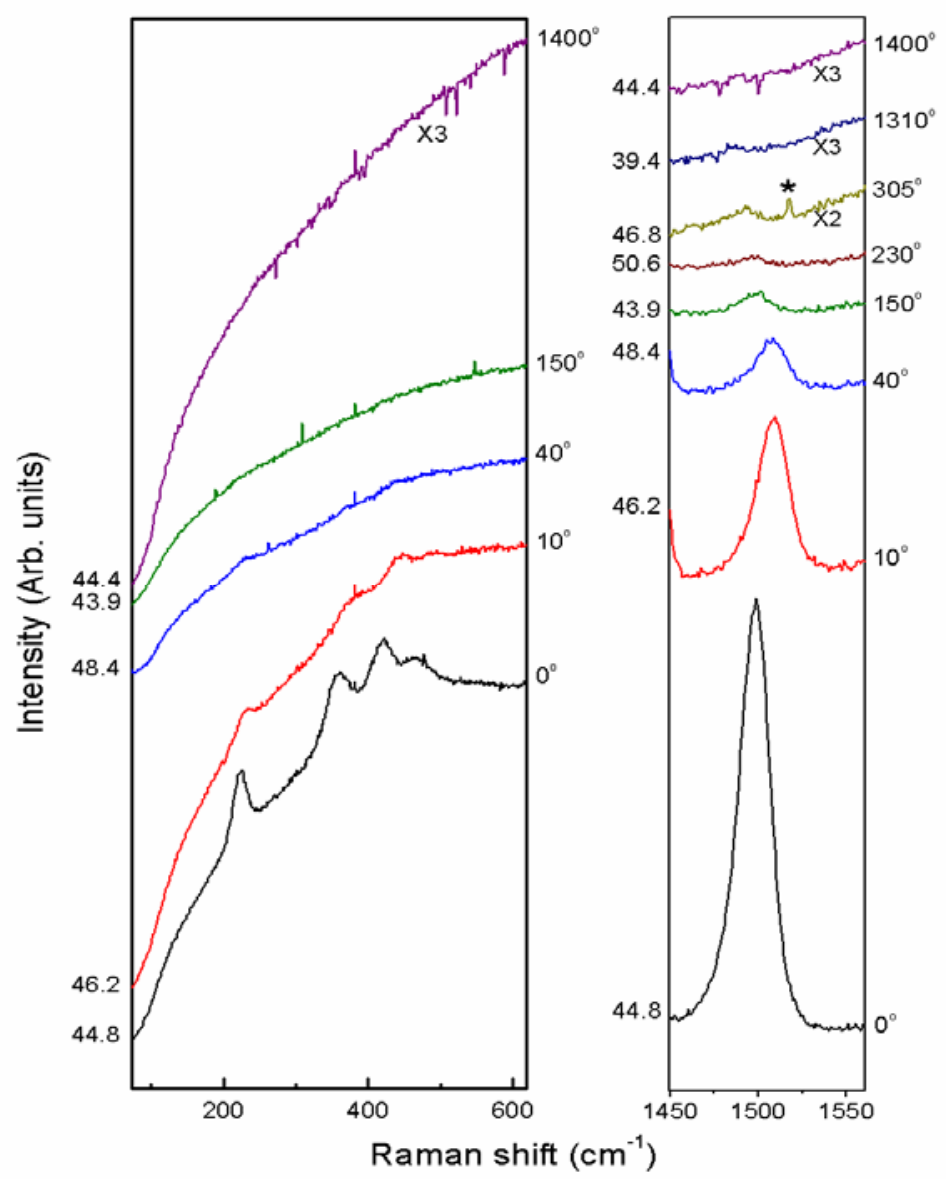

Figure I-4. The Raman spectrum of NaN3 under pressure and shear. The numbers to the left axes marks the pressure in $\mathrm{GPa}$, and those to the right axes are degrees of rotation. 


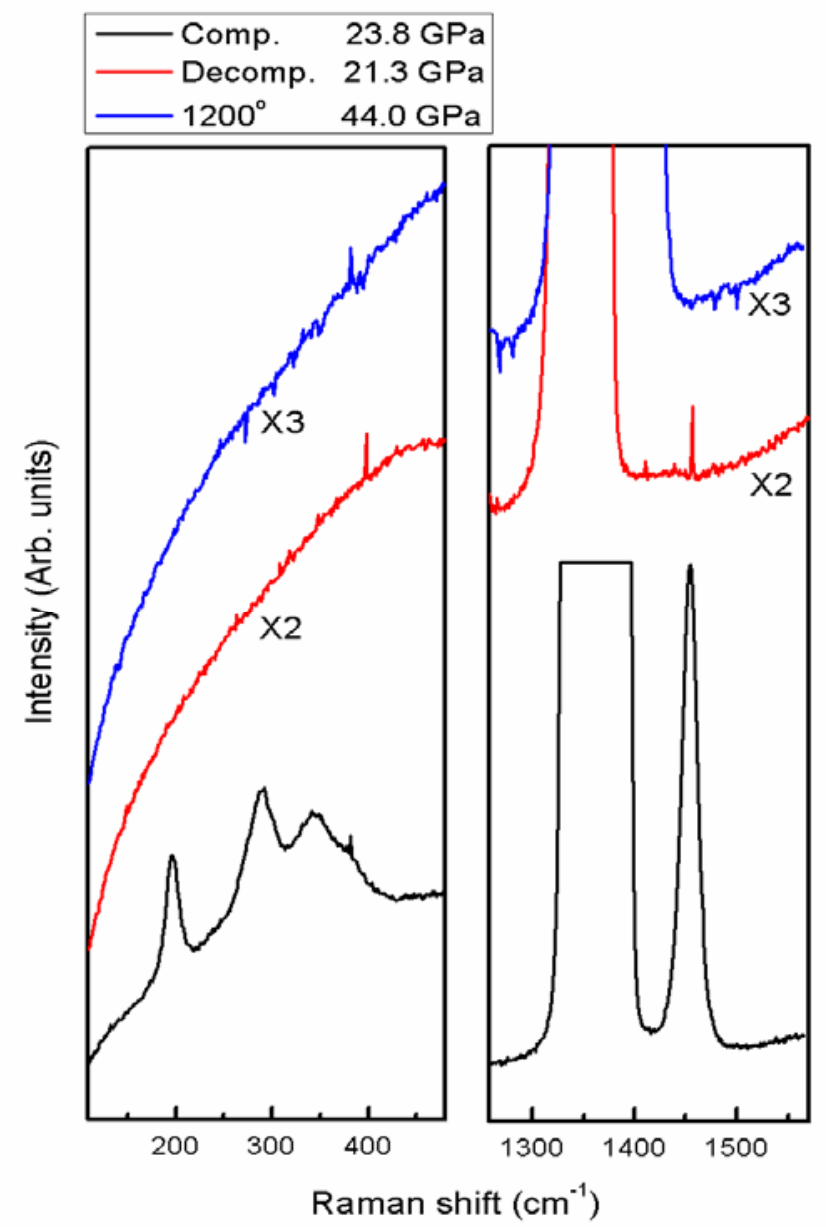

Figure I-5. Raman spectrum of the amorphous phase on pressure quenching, which shows the recovery to the initial phase at $21.3 \mathrm{GPa}$.

(d) Raman measurements of a mixture of $\mathrm{NaN}_{3}$ and $\mathrm{N}_{2}$ under pressure and shear. A mixture of $\mathrm{NaN}_{3}$ and $\mathrm{N}_{2}$ was examined by Raman spectroscopy up to $40.7 \mathrm{GPa}$ in a RDAC. The lattice of $\mathrm{NaN}_{3}$ was altered by the effect of mixing $\mathbf{N}_{2}$ and applying shear, indicated by the new mode in the lattice $\mathrm{m}$ ode region and the split of one m ode into three at $31.7 \mathrm{GPa}$ with $10^{\circ}$ accumulated anvil-rotation (Figure I-6(a)), which was absen $t$ in the $d$ ata obtained by compressing a pure $\mathrm{NaN}_{3}$ (Figure I-6 (b)). We believe that this is a structural phase transition in the NaN3+N2 system, which has not completed at this run of experiment.. Yet, the N-N bonds of both $\mathrm{N}_{3}{ }^{-}$and $\mathrm{N}_{2}$ were not significantly affected by the moderate anvil-rotation $\left(40^{\circ}\right)$, indicated by the preservation of their symm etric stretching modes to the end of the experiments (Figure I6(c) and Figure I-7). The sample got back to the ambient phase upon release of pressure. Further work needs to be done to look into the phase transition and related property changes. 


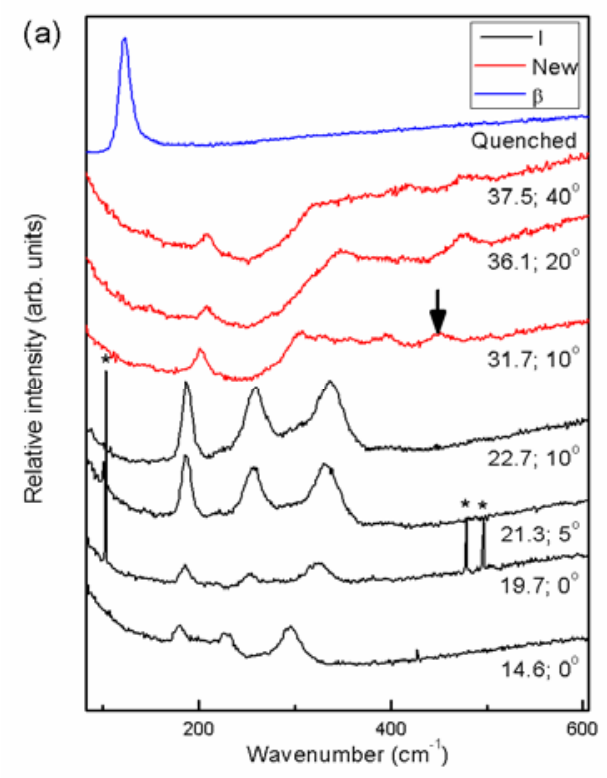

(b)

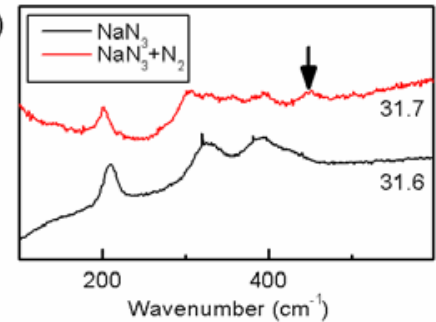

(c)

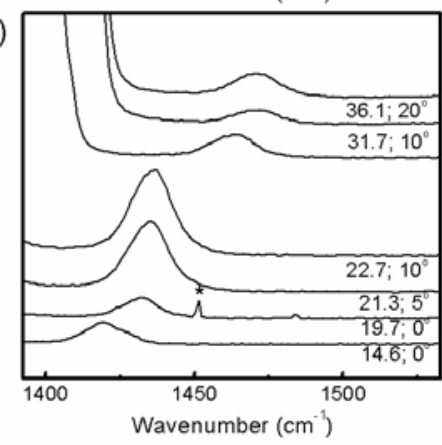

Figure 1-6. Raman shift of modes from $\mathrm{NaN}_{3 .}$ (a) lattice mode region. (b) comparison of spectra between pure $\mathrm{NaN}_{3}$ and mixture of $\mathrm{NaN}_{3}$ and $\mathrm{N}_{2}$. (c) Stretching mode region. Numbers are pressures and accumulated anvil-rotation angles. Asterisks marked spikes are noises.

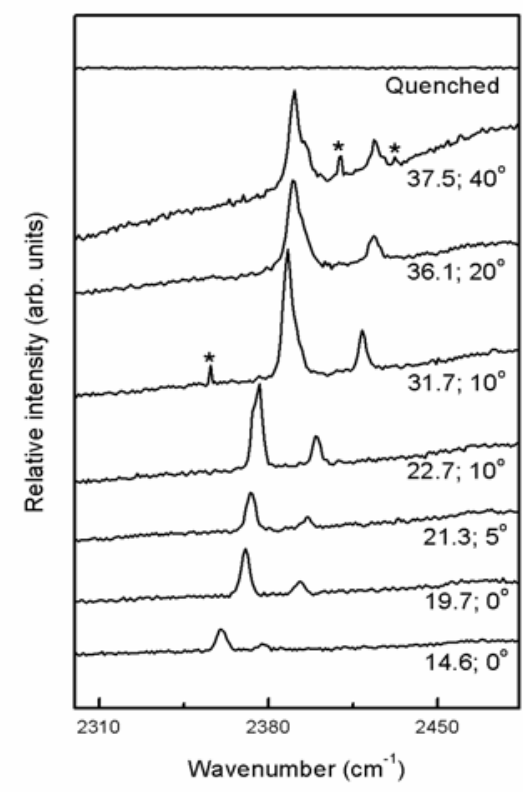

Figure I-7. Raman shift of $\mathrm{N}_{2}$ symmetric stretching modes. Numbers are pressures and accumulated anvil-rotation angles. Asterisks marked spikes are noises.

\section{II. $\mathrm{AgN}_{3}$}

(a) Axial X-ray diffraction measurements of $\mathbf{A g N}_{3}$ [11].

Axial X-ray diffraction measurements were performed to over $50 \mathrm{GPa}$ with different pressure medium (Figures II-1 and II-2). It is found that $\mathrm{AgN}_{3}$ transforms from an orthorhombic to a tetrahedral structure at $0.2 \mathrm{GPa}$, which is stable up to over $50 \mathrm{GPa}$. The high pressure phase is determined to have a I $4 / \mathrm{mcm}$ space group. The structure refinement has been performed and the result are show in table 1 and figure II-3. The structural change at high pressure reflects the relative 3 degree rotations of the $\mathrm{N}$-azide anions (Fig. II-4). The compressibility of the high pressure phase as well as the room pressure phase is determined (Figs II-5 and II-6). While volume is continuous across the transition (see Fig. II-5), like for second-order transformations, the jump in all lattice parameters (Fig. II-6) indicates that this is a first-order phase transformation. 

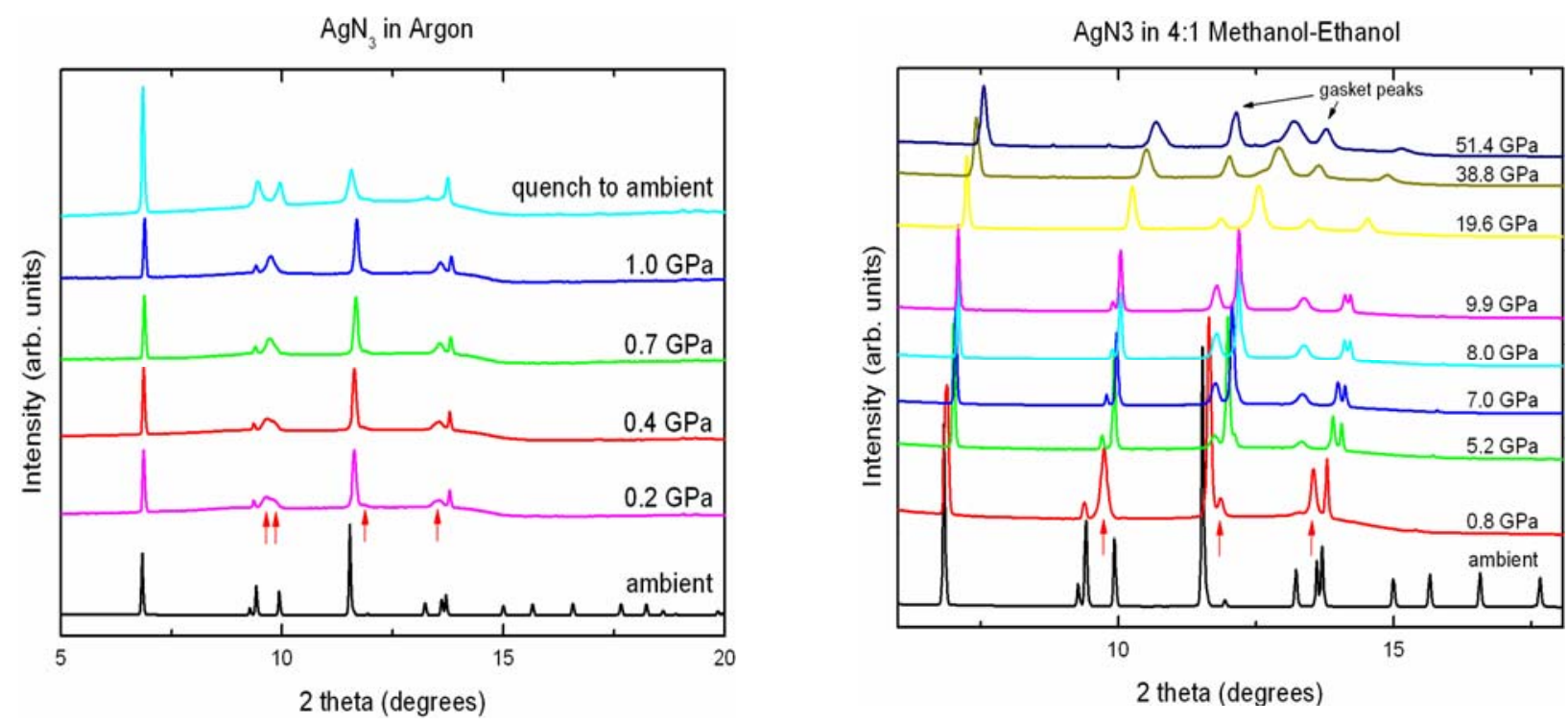

Figure II-1. X-ray diffraction pattern of $\mathrm{AgN}_{3}$ in different pressure media. Arrows point to the emergence of new diffraction peaks corresponding to the phase transformation.

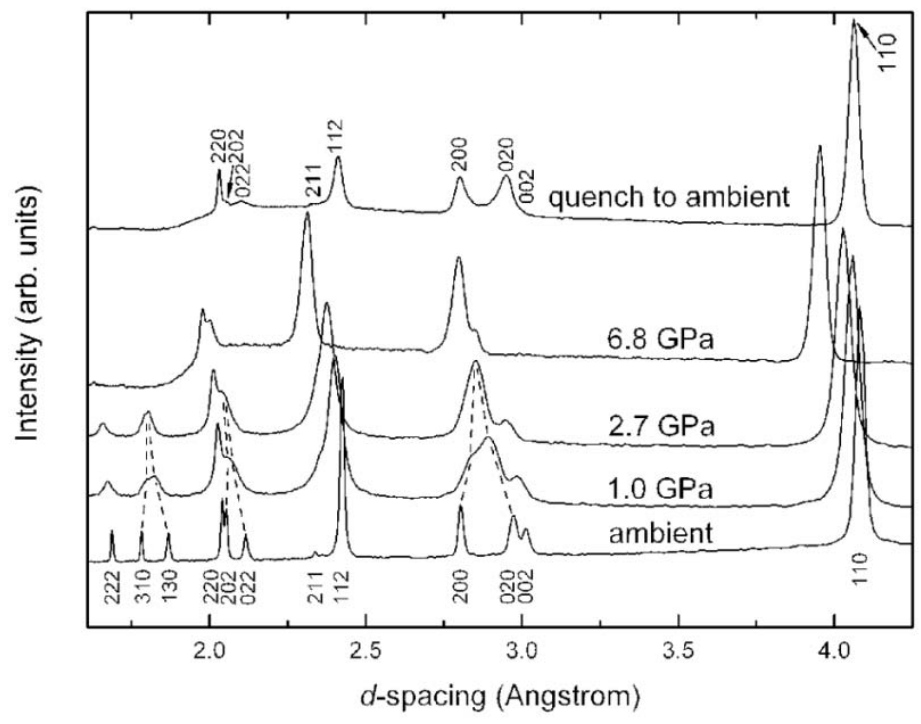

Fig. II-2. The phase transition is signified by the proximity of peaks (020) and (200), (022) and (202), (130) and (310) up to $2.7 \mathrm{GPa}$.

Table II-1. Atomic fractional coordinates of $\mathrm{HP}-\mathrm{AgN}_{3}$ at $13.8 \mathrm{GPa}$

\begin{tabular}{|l|l|l|l|l|}
\hline Atom & Wyck & $\mathbf{x}$ & $\mathbf{y}$ & $\mathbf{z}$ \\
\hline $\mathrm{Ag}$ & $4 a$ & 0 & 0 & 0.25 \\
\hline $\mathrm{N}_{1}$ & $4 d$ & 0 & 0.5 & 0 \\
\hline $\mathrm{N}_{2}$ & $8 h$ & $0.16(2)$ & $0.66(2)$ & 0 \\
\hline
\end{tabular}




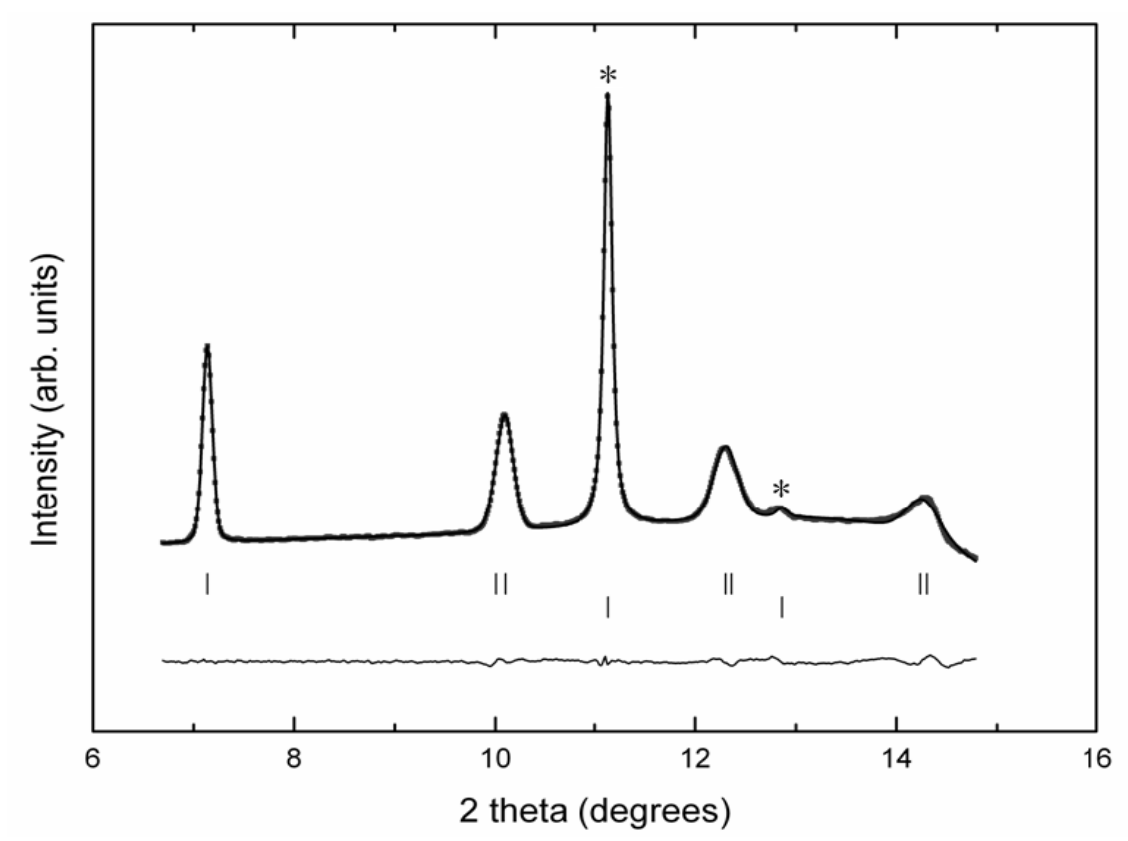

Fig. II-3. Rietveld refinement pattern for $\mathrm{HP}-\mathrm{AgN}_{3}$ at $13.8 \mathrm{GPa}$.

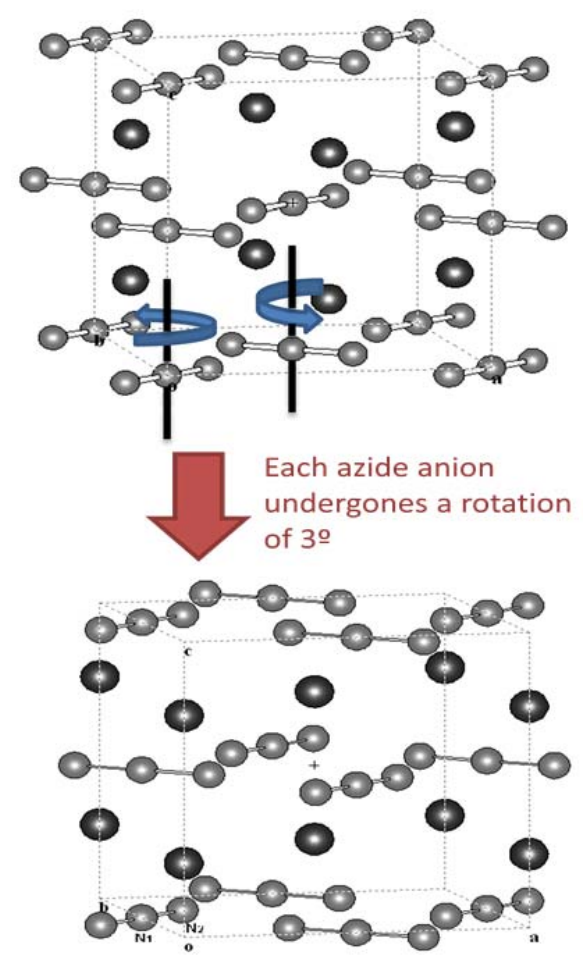

High pressure (HP) $(14 / \mathrm{mcm})$

Figure II-4. The I4/mcm structure of $\mathrm{AgN}_{3}$ reflects a 3 degree rotation of the N3-chain from the original structure. 


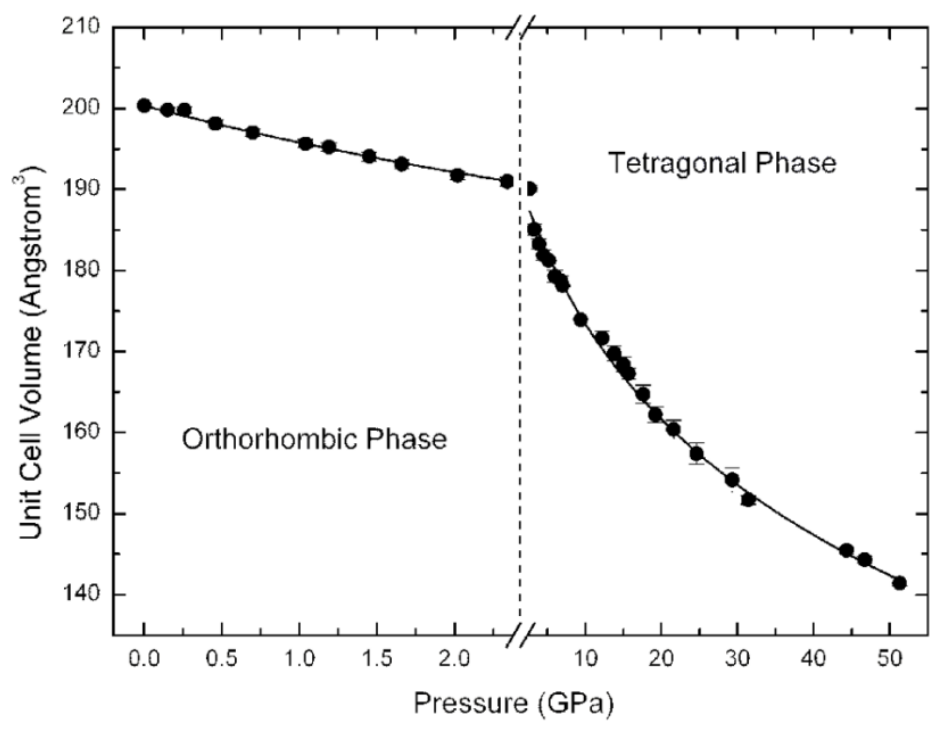

Fig II-5. Phase transition is revealed by the continuous unit cell volume changes with pressure through the transition pressure $(2.7 \mathrm{GPa})$. While volume is continuous across the transition (like for second-order transformation), jump in all lattice parameters (Fig. II-6) indicates that this is a first-order phase transformation.

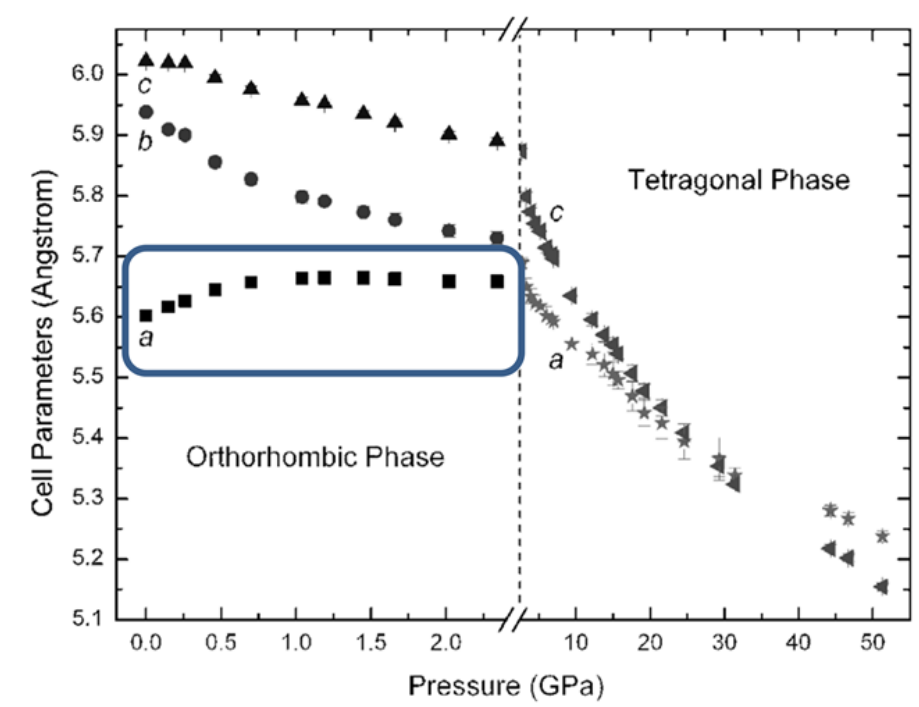

Fig. II-6. An anomalous behavior (expansion) at high pressure is observed in the ambient phase (orthorhombic) of $\mathrm{AgN}_{3}$.

(b) the study of the shear effect on the high pressure phase of $\operatorname{AgN}_{3}$ [25].

In the study of the shear effect on the high pressure phase of $\mathrm{AgN}_{3}$, we performed axial X-ray diffraction study to $31 \mathrm{GPa}$. We compared the diffraction patterns at certain pressures as a result of shear operation with the patterns under relatively same pressure under hydrostatic compression. We found that the shear causes larger d-spacings and broader peak width. The physics behind it is under investigation. 
With the technical development of the radial X-ray diffraction method (discussed in later section), we studied the sear effect on $\mathrm{AgN}_{3}$. With initial pressure of $14.3 \mathrm{GPa}$, after 10 degree of anvil rotation, the pressure increased to $23.0 \mathrm{GPa}$, the diffraction peaks from $\mathrm{AgN}_{3}$ disappeared. $\mathrm{AgN}_{3}$ may possibly become amorphous (Fig. II-7). Since we observed diffraction peaks at similar pressure and larger shear in our axial diffraction measurement, this observation indicated that the amorphization of $\mathbf{A g N}_{3}$ is path-dependent, e.g., i.e., it depends on the entire process of change of pressure and shear.
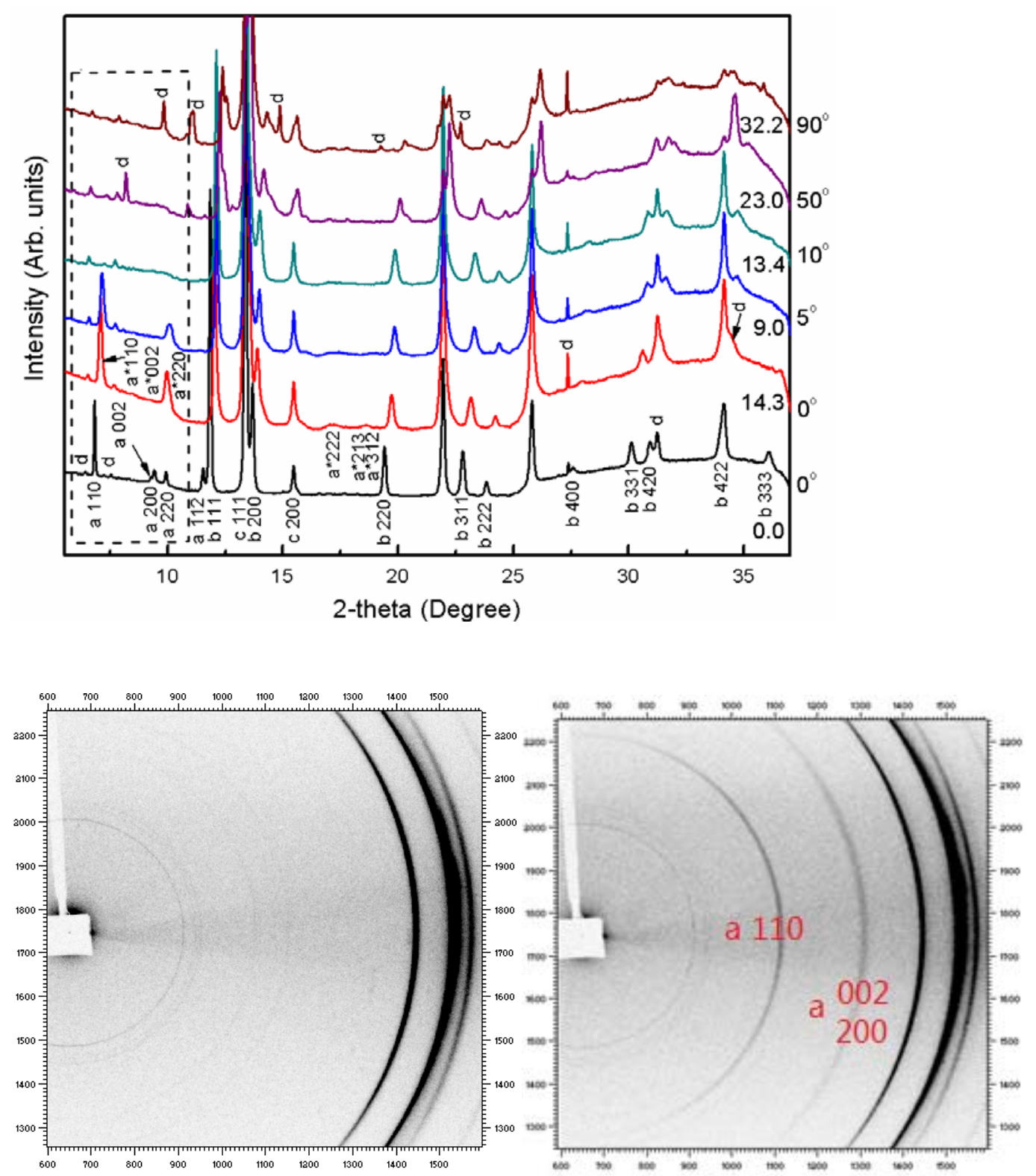

Fig II-7. Radial X-ray diffraction of AgN3 under pressure and shear. Top integrated pattern, bottom, comparision of the diffraction image. $a-\mathrm{AgN}_{3}$ orthorhombic phase, $a^{*}-\mathrm{AgN}_{3}$ tetragonal phase, $b-A u, c-C-B N, d-A n v i l$. 
(c) Raman measurement of $\mathrm{AgN}_{3}$ to 77 GPa with large shear [25].

We performed Raman measurement of $\mathrm{AgN}_{3}$ with large shear. We started to apply shear at $60.8 \mathrm{GPa}$, after 2370 degree of shear, the pressure reached $76.4 \mathrm{GPa}$, where the mode at $1350 \sim 1500 \mathrm{~cm}^{-1}$ and $2250 \sim 2750 \mathrm{~cm}^{-1}$ completed disappeared. This indicates that the sample has been turned to amorphous. Quenching the sample to room pressure, the typical Raman peaks does not reappear, which indicating that the amorphization of $\mathbf{A g N}_{3}$ is quenchable. Detail of the change is shown in Fig. II-8.
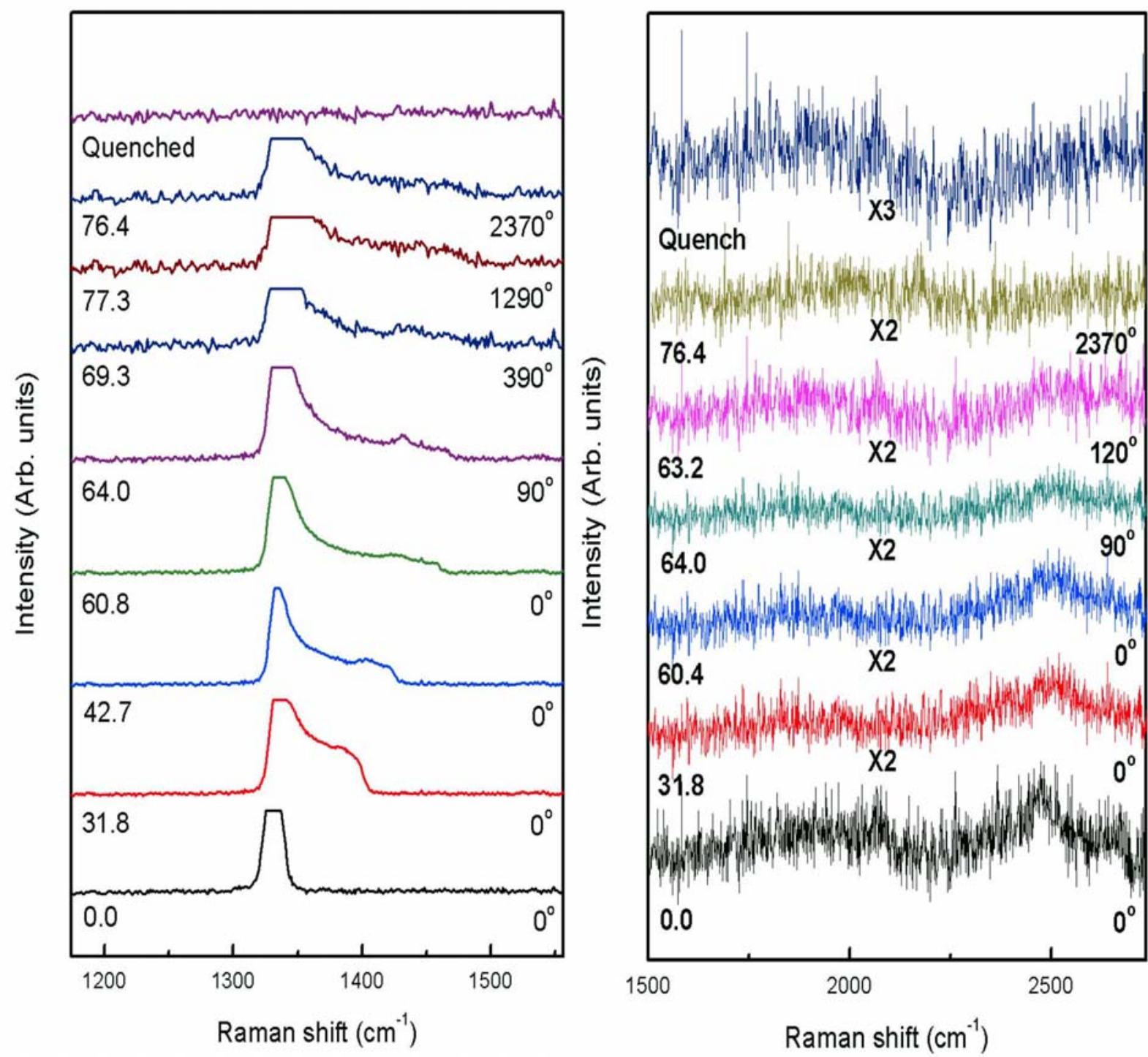

Fig. II-8. Raman spectra of $\mathrm{AgN}_{3}$ under pressure and shear.

\section{III. $\mathrm{KN}_{3}$}

Hydrostatic compression of $\mathrm{KN}_{3}$ up to $55 \mathrm{GPa}$ was performed coupled with synchrotron XRD [12] and Raman spectroscopy techniques [4]. Selected XRD patterns and Raman spectra are 
shown in Figure III-1 and Figure III-2, respectively. The XRD data revealed a phase transition at $15.5 \mathrm{GPa}$, an anisotropic compression, and a very stiff nitrogen chain. The bulk modulus was received as $18.6 \mathrm{GPa}$. The Raman data revealed that the phase transition was related to a soft mode. It also suggests a reduction of symmetry and the loss of inversion center in the HP phase. The mode Grüneisen parameters were obtained as listed in Table III-1.

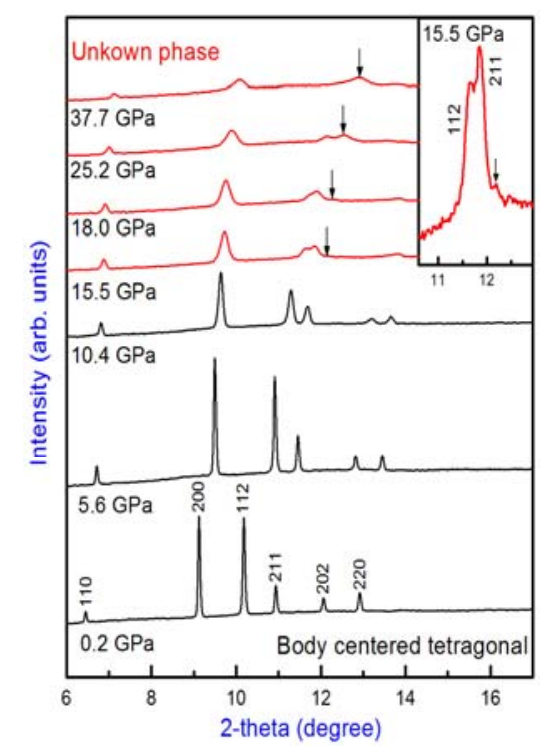

Figrue III-1. The XRD pattern of $\mathrm{KN}_{3}$ under pressures. Inset displays the origination of a new peak which grows with pressure.
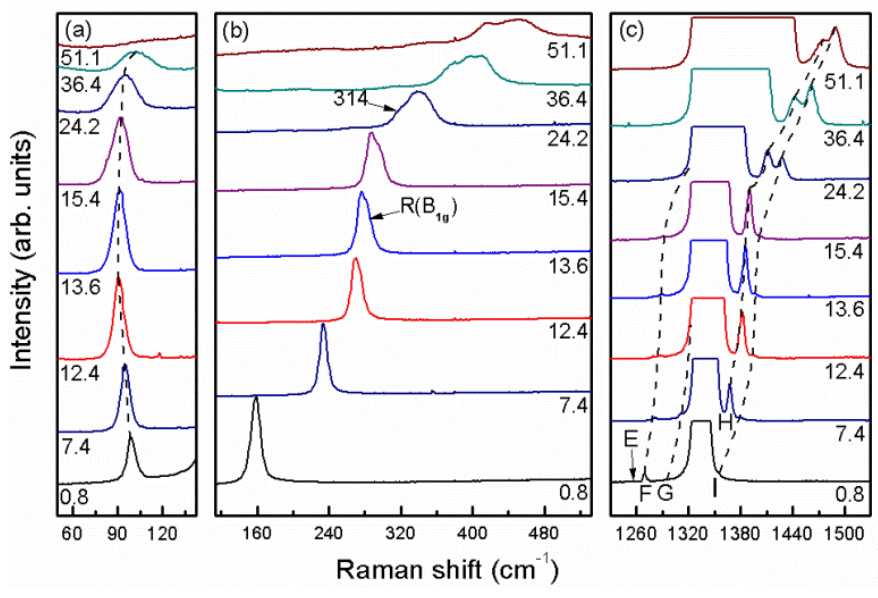

Figrue III-2. The Raman spectra of $\mathrm{KN}_{3}$ under pressures.

Table III-1. Mode frequency, assignm ent, and $\mathrm{m}$ ode Grüneisen parameter of $\mathrm{KN}_{3}$ in its tetragonal phase.

\begin{tabular}{rcc}
\hline \hline $\begin{array}{l}\text { Raman shift } \\
\left(\mathrm{cm}^{-1}\right)\end{array}$ & Assignment & $r_{i}$ \\
\hline 99 & $T\left(E_{g}\right)$ & $-0.139(9)$ \\
145 & $R\left(B_{1 g}\right) \& R\left(E_{g}\right)$ & $0.91(5)$ \\
1255 & $2 v 2\left(A_{l g}\right)$ & $0.040(4)$ \\
1267 & $2 v 2\left(B_{2 g}\right)$ & $0.0229(9)$ \\
1291 & $2 v 2{ }^{\prime}\left(A_{l g}\right)$ & $0.038(2)$ \\
1340 & $v 1\left(B_{2 g}\right)$ & $0.046(2)$ \\
1350 & $v 1\left(A_{l g}\right)$ & $0.050(2)$ \\
\hline \hline
\end{tabular}

\section{IV. $\mathrm{CsN}_{3}$}

The hydrostatic compression of $\mathrm{CsN}_{3}$ to $55 \mathrm{GPa}$ (Fig IV-1) resulted in the discovery of 3 new high pressure phases, which appear at $0.6 \mathrm{GPa}, 4.4 \mathrm{GPa}$, and $15.4 \mathrm{GPa}$ (Figure IV-2) [13]. The phase III is resolved to have a monoclinic crystal structure. The structure work on phase IV and $\mathrm{V}$ is underway. 


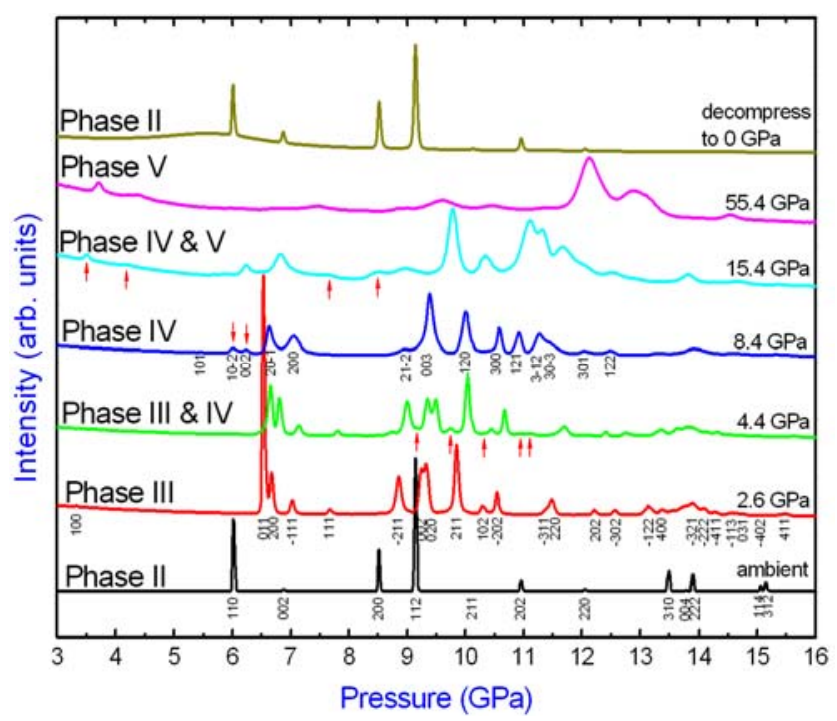

Figure IV-1. XRD of CsN3 at pressures.

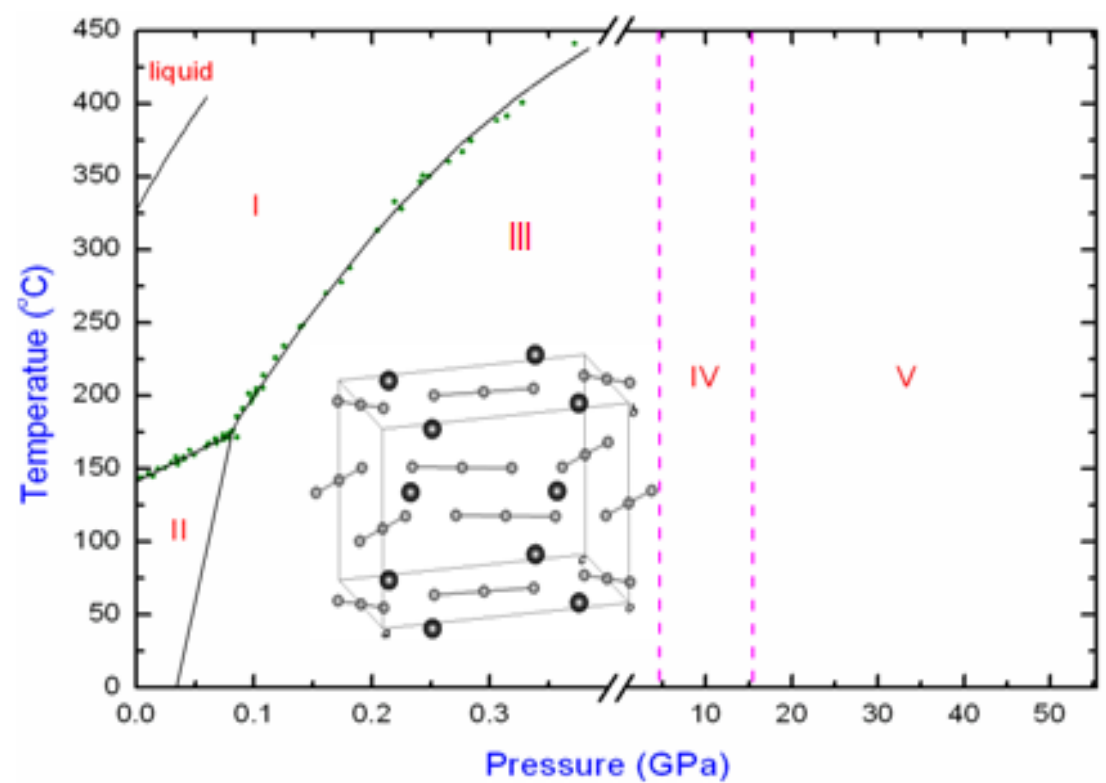

Figure IV-2. The phase diagram of $C s N_{3}$.

\section{Conclusions}

Experimental approaches to study strain-induced phase transformations in potentially energetic materials are refined. Experiments on $\mathrm{NaN}_{3} \mathrm{NaN}_{3}+\mathrm{N}_{2}$ mixture, and $\mathrm{AgN}_{3}$ are performed under hydrostatic compression up to $77 \mathrm{GPa}$ and under shear. Various phase transformations, including amorphization, are obtained in both materials under various compression-shear paths. The first nanoscale theory and simulation technique based on phase field approach is developed and better understanding of the main reasons and mechanisms for plastic strain-induced nucleation and growth of the high-pressure phase is achieved. The macroscale theory and FEM approaches to describe behavior of a sample under compression and 
torsion in RDAC are developed. The results change the fundamental understanding of interpretation of experimentally observed effects and measurements and the extracting of information on material behavior from sample behavior.

The above experimental, theoretical, and computational results represent significant progress toward the strain-induced synthesis of metastable high-pressure phases, including highly energetic phases. 


\section{Journal Publications}

1. Levitas V. I., Levin V. A., Zingerman K. M., and Freiman E. I. Displacive phase transitions at large strains: Phase-field theory and simulations. Physical Review Letters, 2009, Vol. 103, No. 2, 025702; selected and published by the Virtual Journal of Nanoscale Science \& Technology, July 20, 2009 issue. IF: 7.621

2. Levitas V.I., Lee D.-W. and Preston D.L. Interface propagation and microstructure evolution in phase field models of stress-induced martensitic phase transformations.

International J. Plasticity, 2010, Vol. 26 No. 3, 395-422. IF: $\mathbf{5 . 0 8 2}$

3. V. I. Levitas and O. M. Zarechnyy. Modeling and simulation of mechanochemical processes in rotational diamond anvil cell. Europhysics Letters, 2009, Vol. 88, 16004, 1-6. IF: 2.753

4. Ji, C., Hou, D., Zhu, H., Wu, J., Chyu, M., Ma, Y., Pressure-induced Phase Transition in Potassium Azide. Journal of Applied Physics, Accepted. IF: 2.064

5. Levitas V.I. and Zarechnyy O.M. Numerical study of stress and plastic strain evolution under compression and shear of a sample in rotational anvil cell. High Pressure Research, 2010, Vol. 30, No. 4, 652-668. IF: 0.995

6. Levitas V.I. and Zarechnyy O.M. Modeling and simulation of strain-induced phase transformations under compression in a diamond anvil cell. Physical Review B, 2010, Vol. 82, 174123 IF: 3.772

7. Levitas V.I. and Zarechnyy O.M. Modeling and simulation of strain-induced phase transformations under compression and torsion in a rotational diamond anvil cell. Physical Review B, 2010, Vol. 82, 174124 IF: 3.772

8. Levitas V.I. and Javanbakht M. Surface tension and energy in multivariant martensitic transformations: Phase-field theory, simulations, and model of coherent interface. Physical Review Letters, 2010, Vol.105, No.16, 165701. IF: 7.621

9. Levin V. A., Levitas V. I., Lokhin V.V., Zingerman K.M., Sayakhova L.F., Freiman E.I. Displacive phase transitions at large strains: Phase-field theory and simulations. Doklady

Physics, 2010, Vol. 55, No. 10, pp. 507-511. IF: 0.347

11. Hou, D., Zhang, F., Ji, C., Hannon, T., Zhu, H., Wu, J., Levitas, V. I., Ma, Y., Structures of Silver Azide at High Pressure: Phase Transition and Anomalous Compressibility. Journal of Applied Physics, 2011, Vol. 110, 023524. IF: 2.064

12. Ji, C., Zhang, F., Hou, D., Zhu, H., Wu, J., Chyu, M., Levitas, V. I., Ma, Y., High pressure X-ray diffraction study of potassium azide. Journal of Physics and Chemistry of Solids, 2011, Vol. 72, 736-739. IF: 1.381 
13. Hou, D., Zhang, F., Ji, C., Hannon, T., Zhu, H., Wu, J., Ma, Y., Series of phase transitions in cesium azide under high pressure studied by in situ x-ray diffraction. Physical Review B, 2011, Vol. 84, 064127 (2011). IF: 3.772

14. Levitas V.I. and Samani K. Size and mechanics effects in surface-induced melting of nanoparticles. Nature Communications, 2011, Vol. 2, 284. New journal, no impact factor. $\mathbf{8 \%}$ acceptance rate.

15. Levitas V.I. and Javanbakht M. Phase-field approach to martensitic phase transformations: Effect of martensite-martensite interface energy. International Journal of Materials Research, 2011, Vol. 102, No. 6, 652-665. IF: $\mathbf{0 . 8 6 0}$

16. Hou D., Zhang F., Ji C., Hannon T., Zhu H., Wu Z., Levitas V.I., and Ma Y.Phase Transition and Structure of Silver Azide at High Pressure. Journal of Applied Physics, 2011, Vol. 110, 023524. IF: $\mathbf{2 . 0 6 4}$

17. Ji C., Zhang F., Hou D., Zhu H., Wu J., Chyu M.-C., Levitas V.I., and Ma Y. High pressure X-ray diffraction study of potassium azide. J. Physics and Chemistry Solids, 2011, Vol. 72, No. 6, 736-739. IF $\mathbf{1 . 3 8 4}$

18. Levitas V.I. and Javanbakht M. Surface-induced phase transformations: Multiple scale and mechanics effects and morphological transitions. Physical Review Letters, 2011, Vol. 107, 175701. IF: $\mathbf{7 . 6 2 2}$

19. Levitas, V.I. Sublim ation, chemical decomposition, and $\mathrm{m}$ elting inside an elas toplastic material: General continuum thermodynamic and kinetic theory. Int. J. Plasticity, Vol. 34, 41-60, 2012. IF $\mathbf{5 . 0 8 2}$

20. Levitas, V.I. and Altukhova, N. Therm odynamics and kinetics of nucleation of a spherical gas bubble inside an elastoplasti c material due to sublim ation. Int. J. Plasticity, Vol. 34, 12-40, 2012. IF $\mathbf{5 . 0 8 2}$

21. Zarechnyy O. M., Levitas V.I., and Ma, Y. Coupled plastic flow and phase transformation under compression of materials in a diamond anvil cell: Effects of transformation kinetics and yield strength. Journal of Applied Physics, 2012, Vol. 111, 023518. IF 2.79

22. Cho J.-Y., Idesman A. V., Levitas V. I., and Park T. Finite element simulations of dynamics of multivariant martensitic phase transitions based on Ginzburg-Landau theory. International Journal of Solids and Structures, 2012, http://dx.doi.org/10.1016/j.ijsolstr.2012.04.008. IF 1.677

23. Zhu, H., Zhang, F., Hou, D., Ji, C., Wu, J., Trevor, H., Ma, Y., Phase transitions of sodium azide under high pressure. Applied Physics Letter, submitted. IF: 3.820

24. Ji, C., Zhu, H., Zheng, R., Levitas, V. I., Ma, Y., Shear-induced amorphization of sodium aizde. Manuscript in preparation. 
25. Zhu, H., Hou, D., Ji, C., Levitas, V. I., Ma, Y., Irreversible amorphization of silver azide induced by plastic shear, Manuscript in preparation.

\section{Book Chapter}

Levitas V.I. Apparent and Hidden Mechanochemistry. In: Experimental and Theoretical Studies in Modern Mechanochemistry, pp. 41-56 Eds. F. Delogu and G. Mulas (Research Signpost, 2010).

\section{Presentations at meetings, conferences, seminars}

1. Levitas V. I. Mechanochemistry: Experiments, Multiscale Theory, and New Mechanisms of Phase Transformations and Chemical Reactions in Solids (invited lecture). Army Research Laboratory, Aberdeen Proving Ground, MD, 2009.

2. Levitas V.I. Mechanochemistry: Experiments, Multiscale Theory, and New Mechanisms of Phase Transformations and Chemical Reactions in Solids (invited lecture). Armament Research, Development and Engineering Center (ARDEC), Picatinny, N.J., 2009.

3. Levitas V.I. Phase Field and Micromechanical Modeling of Martensitic Phase Transformations (keynote lecture). International Symposium on Plasticity'09, St. Thomas, U.S. Virgin Islands.

4. Levitas V.I. Nano- and Macro-scale Phase Field Modeling of Phase Transformations (invited lecture). IV European Conference on Computational Mechanics May 16-21, 2010, Paris, France.

5. Levitas V.I. Effect of large plastic deformations under high pressure on phase transformations. Plasticity'10 International Symposium (keynote lecture). St. Kitts Marriott Resort, West Indies, January 3-8, 2010.

6. Levitas V. I. Strain-Induced Phase Transformations under High Pressure: Recent Results, Challenges, and Perspectives (invited lecture). Institute for Superhard Materials of the Ukrainian National Academy of Sciences, June 7, 2010.

7. Levitas V. I. Mechanochemistry: Experiments, Multiscale Theory, and New Mechanisms of Phase Transformations in Solids (invited lecture). University of Minnesota, Minneapolis, MN, March 9, 2010.

8. Levitas V. I. Nano- and Macro-scale Phase Field Modeling of Martensitic Phase Transformations. 16th U.S. National Congress of Theoretical and Applied Mechanics, Penn State, State College, Pennsylvania, July 28, 2010.

9. Javanbakht M. Interface propagation and microstructure evolution in surface-induced multivariant phase transformations based on phase field models. Excellence of Graduate Research Conference at ME Department of ISU, April 29, 2010.

10. Samani K. Phase Field Modeling of Melting of Aluminum Nanoparticles. Excellence of Graduate Research Conference at ME Department of ISU (2 ${ }^{\text {nd }}$ Award), April 29, 2010. 11. Levitas V. I. Stress- and Strain-Induced Phase Transformations in Solids (invited lecture). Army Workshop on Intelligent and Active Protective Systems for Dynamic Load Mitigation, Aberdeen, MD, May 27, 2010.

12. V. I. Levitas. Search for New Highly Energetic Phases under Compression and Shear. DTRA grantee meeting. Washington, DC, 2010. 
13. V. I. Levitas. Phase field theory for phase transformations at large strains and with surface effects. 47th Annual Meeting Society of Engineering Science, Ames, IA, 2010. (Invited talk).

14. K. Samani and V. I. Levitas. Phase field modeling of melting of aluminum nanoparticles. 47th Annual Meeting Society of Engineering Science, Ames, IA, 2010.

15. M. Javanbakht and V. I. Levitas. Effect of surface tension and energy on multivariant phase transformations based on phase field approach. 47th Annual Meeting Society of Engineering Science, Ames, IA, 2010.

16. O.Zarechnyy and V. I. Levitas. Modeling and simulation of strain-induced phase transformations in rotational diamond anvil cell under compression and torsion. 47th Annual Meeting Society of Engineering Science, Ames, IA, 2010.

17. Nano- and Micro-Scale Phase Field Modeling of Phase Transformations. V. I. Levitas (keynote lecture), Plasticity'11 International Conference, PuertoVallarta, January 3-8, 2011.

18. M. Javanbakht. Phase-Field Approach to Martensitic Phase Transformations: Effect of Surface Tension, Interface Energy, FEM Discretization, and Size Effect. 2011 Excellence of Graduate Research Conference, Iowa State University, Dept. of Mechanical Engineering, Ames, IA, March 31, 2011. Supervisor: V. Levitas

19. K. Samani, Melting of nanoparticles: surface, size and mechanics effects. 2011 Excellence of Graduate Research Conference, Iowa State University, Dept. of Mechanical Engineering, Ames, IA, March 31, 2011. Supervisor: V. Levitas

20. Yanzhang Ma, Dongbin Hou, Fuxiang Zhang, Cheng Ji, Trevor Hannon, Hongyang Zhu, Jianzhe Wu, High Pressure Phase Transitions of Cesium Azide, SMEC2011, March 2011 Miami, FL.

21. Yanzhang Ma, Cheng Ji , Fuxiang Zhang, Dongbin Hou, Hongyang Zhu, Jianzhe Wu, Ming-Chien Chyu, Behavior of potassium azide under high pressure, SMEC2011, March 2011Miami, FL.

22. Valery I. Levitas. Phase Field Approach for Solid-solid and Solid-liquid Phase Transformations: Large Strains and Surface Effects (invited lecture). ASME Applied Mechanics and Materials Conference, Chicago, IL, May 30 - June 1, 2011.

23. K. Samani and V. I. Levitas. Phase Field Modeling of Melting of Aluminum Nanoparticles, Surface, Size, High Heating Rate, and Mechanics Effects. ASME Applied Mechanics and Materials Conference, Chicago, IL, May 30 - June 1, 2011.

24. O. Zarechnyy and V. I. Levitas. Modeling and simulation of strain-induced phase transformations under compression and torsion in a rotational diamond anvil cell. ASME Applied Mechanics and Materials Conference, Chicago, IL, May 30 - June 1, 2011.

25. M. Javanbakht and V. I. Levitas. Phase field approach to multi-variant phase transformations: Effect of surface tension and energy. ASME Applied Mechanics and Materials Conference, Chicago, IL, May 30 - June 1, 2011.

26. V. I. Levitas. Strain-Induced Phase Transformations under Compression and Shear of Materials in Rotational Diamond Anvil Cell (Closing Keynote Lecture). International Conference on High Pressure Effects on Materials, Kiev, Ukraine, June 29 -30, 2011.

27. V. I. Levitas. Search for New Highly Energetic Phases under Compression and Shear. DTRA grantee meeting. Washington, DC, July 28, 2011.

28. V. I. Levitas. Effect of Stresses and Plastic Strains on Some Phase Transformations (invited lecture), NIST, July 27, 2011. 
29. Levitas V.I. Phase Field Theory and Simulations for Stress-Induced Solid-Solid Phase Transformations and Melting: Large Strains and Surface Effects. 48th Annual Meeting Society of Engineering Science, Evanston, IL, 10/12/11-10/14/11.

30. M. Javanbakht and V. I. Levitas. Effect of surface tension and energy on multivariant phase transformations: phase field approach. 48th Annual Meeting Society of Engineering Science, Evanston, IL, 10/12/11-10/14/11.

31. K. Samani and V. I. Levitas. Coherent interface with stress relaxation in phase-field approach for melting-solidification. 48th Annual Meeting Society of Engineering Science, Evanston, IL, 10/12/11-10/14/11.

32. V. I. Levitas. Surface-induced phase transformations and phenomena: Phase Field Approach (keynote lecture), Plasticity'12 International Conference, Puerto Rico, USA, January 3-8, 2012.

33. Y. Ma and V. I. Levitas. Structural phase transformations under pressure and plastic shear (keynote lecture), Plasticity'12 International Conference, Puerto Rico, USA, January 3-8, 2011.

34. V. I. Levitas. Strain-Induced Phase Transformations under Compression and Shear in Rotational Diamond Anvil Cell (invited lecture). TMS 2012 Annual Meeting, Orlando, Florida, March 8-14, 2012.

35. V. I. Levitas. Phase Field Approach to Stress-Induced Solid-Solid and Solid-Liquid Phase Transformations. TMS 2012 Annual Meeting, Orlando, Florida, March 8-14, 2012.

36. V. I. Levitas. Search for Unprecedented Materials Properties, Mechanisms, and Phenomena. Texas Tech University, Lubbock, TX, May 2011 (invited lecture).

37. V. I. Levitas. Phase Field Approach to Melting, Martensitic Phase Transformations, and Twinning. Ames Laboratory, Ames, IA, September 23, 2011 (invited lecture).

38. V. I. Levitas. Nanomechanics of Phase Transformations. Institute for Superhard Materials, Kiev, Ukraine, December 9, 2011 (invited lecture).

39. V. I. Levitas. Search for Unprecedented Materials Properties, Mechanisms, and Phenomena. Florida Atlantic University, Boca Raton, FL, April, 16, 2012 (invited lecture).

Levitas V.I. developed and taught a new graduate distance education course "Phase Transformations in Elastic Materials," which included phase field approaches to phase transformations in solids and surface phenomena, developed in the project.

\section{Short Courses}

Levitas V.I. Six invited lectures on Mechanically-Induced Phase Transformations and Chemical Reactions." Advanced School "Plasticity and Beyond: Microstructures, CrystalPlasticity and Phase Transitions." 06/27 - 07/01/2011. International Centre for Mechanical Sciences, (CISM, Udine, Italy). 


\section{Honor and Awards}

\section{V.I. Levitas}

1. Alexander von Humboldt Foundation (Germany) Fellowship for alumni for 3 months research in Germany, including support for post doc from the USA, 2012.

2. Honorary Doctor in Materials of the Institute for Superhard Materials, Kiev, Ukraine, 2011.

3. Lifetime Achievement Award for outstanding achievements in engineering, science, and education, International Biographical Centre, Cambridge, UK, 2010.

4. The Da Vinci Diamond for inspirational and outstanding achievements in engineering, science, and education, International Biographical Centre, Cambridge, UK, 2010.

5. Lifetime Achievement Award, World Congress of Arts, Sciences and Communications, 2009.

6. Einstein Award for Scientific Achievement, International Biographical Centre, 2009.

Listed in:

1. 2010, 2011, 2012 Who's Who in the World.

2. 2008 IBC Foremost Scientists of the World, International Biographical Centre, Cambridge, England.

3. 2008 Leading Scientists of the World, International Biographical Centre, Cambridge, England.

4. 2009 Dictionary of International Biography.

5. 20092000 Outstanding Scientists 2008/2009, International Biographical Centre, Cambridge, England.

6. 2008 and 2011 Who's Who in Science and Engineering

7. 2010, 2011, and 2012 Who's Who in America

8. 2008 Top 100 Scientists 2008, International Biographical Centre, Cambridge, England.

9. 2008 Asian-American Who's Who.

10. 2009 Asian-Pacific Who's Who.

\section{Yanzhang Ma}

Ed and Linda Whitacre Faculty Fellow, College of Engineering, Texas Tech University, 20112014.

\section{Organization of Symposiums (Valery Levitas)}

1. Symposium on phase transformations at Plasticity'10 Int. Conference (St Kitts), $01 / 2010$.

2. 47th Annual Meeting Society of Engineering Science, Ames, IA, 2010. Member of the Organizing Committee and Track Chair for Mechanics of Materials and Structures.

3. Symposium on phase transformations and mechanochemistry at Plasticity'11 Int. Conference (Puerto Vallarta, Mexico), 01/2011.

4. Symposium on Mechanics and Physics of Structural Changes in Materials at Plasticity'12 International Conference (San Juan, Puerto Rico, USA), 01/2012.

Professional personnel supported by and/or associated with the research effort Prof. Valery I. Levitas (Iowa State University)

Prof. Yanzhang Ma (Texas Tech University) 
Dr. Oleg Zarechnyy (Defended his $\mathrm{PhD}$ at Texas Tech University under supervision of Dr. Levitas in Spring 2009 and then worked on the project as a Post-Doc Iowa State University). Mahdi Javanbakht and Kamran Samani, PhD students at Iowa State.

Cheng Ji, Dongbin Hou, Hongyang Zhu, and Jianzhe Wu, graduate students at TTU.

Dr. Zhishan Liu and Hongyang Zhu post doc.

Qiliang Cui, Huaxiang Fu, visiting scholar.

Collaboration on phase field modeling:

Prof. Vladimir A. Levin (Department of Mechanics and Mathematics, Lomonosov Moscow State University, Moscow, 119899 Russian Federation)

Konstantin M. Zingerman (Department of Applied Mathematics and Cybernetics, Tver State University, Tver 170100 Russian Federation)

Eugene I. Freiman (Department of Mechanics and Mathematics, Tula State University, Tula 300600 Russian Federation)

Dr. Dean Preston (LANL)

\section{Students Awards}

1. M. Javanbakht. Effect of surface tension and energy on multi-variant phase transformations based on phase field approach. 47th Annual Meeting Society of Engineering Science, Ames, IA, 2010: Second Award in the graduate student competition.

2. K. Samani, Phase field modeling of melting of aluminum nanoparticles. 2nd Excellence of Graduate Research Conference, Iowa State University, Dept. of Mechanical Engineering, Ames, IA, April 29, 2010. Second Award

3. M. Javanbakht. Iowa State University Research Excellence Award

4. K. Samani. Iowa State University Research Excellence Award

\section{Additional support for performing the above work was provided by:}

1. Army Research Office, W911NF-09-1-0001 (\$447,170). PI: Levitas V.I. Co-PI Ma Y. December 2008- December 2012

2. National Science Foundation, CMMI-0969143 (\$306,000 with REU supplement). PI: Levitas V.I., July 2010- June 2013.

3. Start up for Levitas V.I. at ISU.

4. Student support at TTU. 